\title{
Multidisciplinary Approach in Rehabilitation of Special Children
}

\author{
Mahboob UR Rahman* \\ Department of Physiotherapy, Gandhara University, Pakistan \\ *Corresponding Author: Mahboob UR Rahman, Department of Physiotherapy, Gandhara University, Pakistan.
}

Received: October 14, 2019; Published: October 29, 2019

DOI: $10.31080 /$ ASOR.2019.02.0120

Abdullah at the age of 15 with mild physical and mental impairment. He was presented at Habib Physiotherapy Complex for the rehabilitation with the following; First he was having behavior problem being hyper active, non-serious at home and in class room affecting his studies, secondly he was having impaired gait and walking on toes due to tight Achilles tendon, her sister also complaints that the child had some stomach problem having not regular food and bowel disturbance He cannot hear properly and also vision problem and eye sore.

Being looking in to all his issues he was sent to gastroenterologist for the stomach problem where he prescribed some medicine and diagnosed him as IBS. Then referred to ophthalmologist where he advised medicine for his eye problem to be continued for an year, then the ENT surgeon examined him for his hearing issue and advised PTA hearing test where it was done at Habib Physiotherapy Complex and our rehabilitation facility. This test was done and the report was that he has a mild hearing problem and no need of any device, furthermore physiotherapy was extended for his bilateral foot problem, tight Achilles tendon and orthotic support was also given and such his walking issue was addressed. For his behavior problem the psychologist extended support and provided four five sessions.

Will you believe that her sister says previously while he was walking in the street, the people were heard to say that camel is walking, but now everybody says that Abdullah is walking like a normal gentleman. He is now going regular to his school with much better behavior at home and in class His stomach is ok with medication and now he is also look like a normal person.

\section{Conclusion}

Multidisciplinary approach is needed for rehabilitation of cerebral palsy children. Key words: Physiotherapy, Psychotherapy, Orthotics, Medication; multidisciplinary [1-10].

\section{Bibliography}

1. Goossens C. "Aided Communication Intervention Before Assessment: A Case Study of a Child with Cerebral Palsy". Augmentative and Alternative Communication 5.1 (1989): 14-26.
2. Darrah J., et al. "Context therapy: A new intervention approach for children with cerebral palsy". Developmental Medicine and Child Neurology 53.7 (2011): 615-620.

3. Papavasiliou AS. "Management of motor problems in cerebral palsy: A critical update for the clinician”. European Journal of Paediatric Neurology 13.5 (2009): 387-396.

4. JP Dormans and L Pellegrino B. "Caring for Children with Cerebal Palsy: A Team Approach. pdf. H. Brookes Publishing (1998): 533.

5. Molenaers G., et al. "A multilevel approach to botulinum toxin type A treatment of the (ilio)psoas in spasticity in cerebral palsy". European Journal of Neurology 6.4 (1999): s59-s62.

6. Santoro A., et al. "A proposed multidisciplinary approach for identifying feeding abnormalities in children with cerebral palsy". Journal of Child Neurology 27.6 (2012): 708-712.

7. Scholtes VA., et al. "The Combined Effect of Lower-Limb Multilevel Botulinum Toxin Type A and Comprehensive Rehabilitation on Mobility in Children with Cerebral Palsy: A Randomized Clinical Trial". Archives of Physical Medicine and Rehabilitation 87.12 (2006):1551-1558.

8. Spittle AJ and Orton J. "Cerebral palsy and developmental coordination disorder in children born preterm". Seminars in Fetal and Neonatal Medicine 19.2 (2014): 84-89.

9. Technique DA., et al. "Oysphagia Dysphagia in Cerebral Palsy". A Comparative Study of the Exeter 219 (1992): 209-219.

10. Becher JG. "Pediatric Rehabilitation in Children with Cerebral Palsy". Journal of Prosthetics and Orthotics 14.4 (2002): 143149.

\section{Volume 2 Issue 11 November 2019 \\ (C) All rights are reserved by Mahboob UR Rahman.}

